Engineering and Computational Mechanics Volume 167 Issue EM1

Simulation of repository gas migration in a bentonite buffer

Vardon, Thomas, Masum, Chen and Nicholson
Proceedings of the Institution of Civil Engineers Engineering and Computational Mechanics 167 March 2014 Issue EM1 Pages 13-22 http://dx.doi.org/10.1680/eacm.12.00018

Paper 1200018

Received 29/12/2012

Published online 11/12/2013

Accepted 28/01/2013

Keywords: mathematical modelling/nuclear power/waste management \& disposal

ICE Publishing: All rights reserved

\title{
Simulation of repository gas migration in a bentonite buffer
}

1 Philip James Vardon MEng, PhD

Assistant Professor, Geo-Engineering Section, Department of Engineering and Geoscience, Delft University of Technology, Delft, the Netherlands

2. Hywel Rhys Thomas MSC, DIC, PhD, DSC, FREng, FRS, CEng, FICE, FGS

Professor and Director, Geoenvironmental Research Centre, Cardiff University, Cardiff, UK
3 Shakil Al Masum MEng, PhD

Research Assistant, Geoenvironmental Research Centre, Cardiff University, Cardiff, UK

4 Qing Chen MSc, FGS

Senior Hydrogeologist, Ove Arup \& Partners, London, UK

5 Duncan Nicholson MSC, DIC, CEng, MICE Director, Ove Arup \& Partners, London, UK


The inventory of high-level radioactive waste in the UK is likely to be disposed of in a geological disposal facility, which will generate gases due to processes such as anoxic metal corrosion and water radiolysis. Such gases have the potential to migrate through the repository system and may be detrimental to the engineered barrier system by damaging the physical fabric of the buffer material through the build-up of pressure. An investigation into the migration of gases and the ranges of gas pressures expected in such a repository is presented. A model of gas transport is presented to simulate the transport of gases in conjunction with coupled thermo-hydro-chemical-mechanical processes. This model includes a boundary condition linking the corrosion behaviour to gas generation and water supply. A realistic range of gas generation rates has been established from available data alongside realistic ranges of material properties of a bentonite buffer. Numerical simulations were then undertaken for a range of realistic scenarios considering the corrosion processes and buffer properties. It was found that in all realistic cases, including realistic maxima and minima considered, the risk of pneumatic fracture was negligible.

\section{Notation}

$c_{\mathrm{d}}^{i} \quad$ liquid phase chemical species concentration (chemical species $i$ )

$c_{\mathrm{g}}^{i} \quad$ gas phase chemical species concentration

$D$ diffusivity coefficient

d factor representing the decrease in corrosion rate with relative humidity

$f_{\mathrm{Fe}} \quad$ fraction of iron in the steel

$K \quad$ hydraulic or gas conductivity

$K_{\mathrm{H}} \quad$ Henry's coefficient of solubility

M molecular weight

$m \quad$ stoichiometric factor

$N \quad$ number of gas species

$q_{\mathrm{g}} \quad$ gas flux

$q_{\mathrm{w}} \quad$ water flux

$R \quad$ universal gas constant

$R_{\mathrm{C}} \quad$ corrosion rate

$R_{\mathrm{g}} \quad$ maximum gas flux

$R_{\mathrm{m}} \quad$ gas generation rate

$R_{\mathrm{w}} \quad$ maximum water flux
$R_{\mathrm{d} \rightarrow \mathrm{g}}^{i} \quad$ sink/source term of chemical species $i$ from dissolved to gas form

$R_{\mathrm{g} \rightarrow \mathrm{d}}^{i} \quad$ sink/source term of chemical species $i$ from gas to dissolved form

$S \quad$ reactive surface area

$\mathrm{Sr}$ degree of saturation

$\mathrm{Sr}_{\mathrm{c}} \quad$ critical degree of saturation

$T$ temperature in $\mathrm{K}$

$t$ time

$\boldsymbol{u}$ deformation

$u_{\mathrm{g}} \quad$ pore gas pressure

$u_{1} \quad$ pore water pressure

$\partial V \quad$ incremental volume

$v_{\mathrm{g}} \quad$ advective gas flux

$v_{1} \quad$ Darcy flux

$v_{\mathrm{dg}}^{i} \quad$ diffusive gas flux

$v_{\mathrm{dl}}^{i} \quad$ diffusive chemical flux

$v_{\mathrm{g}}^{i} \quad$ advective gas species flux

$v_{1}^{i} \quad$ advective chemical species flux

$\alpha \quad$ ratio of molecular weights 


$\begin{array}{ll}\gamma & \text { unit weight } \\ \theta_{\mathrm{g}} & \text { gas saturation } \\ \theta_{1} & \text { liquid saturation } \\ \rho & \text { density }\end{array}$

\section{Introduction}

High-level radioactive waste (HLW) exists throughout the world, mainly as a result of power generation. It is a heat-producing, long-lasting waste, characterised by low volumes and high radioactivity. For example, in the UK, HLW contains $92 \%$ of the radioactivity and only $2 \%$ of the waste volume of the radioactive waste inventory (CoRWM, 2006). The most likely long-term disposal option is deep geological disposal, where the waste is contained at approximately $500 \mathrm{~m}$ depth. The HLW will be contained within a multi-barrier system (e.g. Norris, 2009) in which, usually, the waste is vitrified, contained within a metallic canister, and then placed into a geological disposal facility (GDF), surrounded by a compacted clay buffer of high swelling potential and low permeability (e.g. Norris, 2009).

In the initial period after the waste has been installed in the GDF and the GDF has been sealed, the thermal, hydraulic and mechanical behaviour is of importance for the analysis of safety (e.g. Thomas et al., 2012; Yong et al., 2010). In particular, the initial hydration of the compacted clay buffer is important and it is governed by the coupled thermal-hydraulic-mechanical (THM) behaviour. Following hydration of the clay buffer, which may take tens to hundreds of years, anaerobic corrosion of the metallic components may occur. At this point, heat generation from the waste will be reduced, so that water is not as readily converted to vapour and transported away from the canister. Several gas species may be generated - hydrogen $\left(\mathrm{H}_{2}\right)$, helium $(\mathrm{He})$, water vapour, carbon dioxide $\left(\mathrm{CO}_{2}\right)$ and methane $\left(\mathrm{CH}_{4}\right)$ - although hydrogen from metallic corrosion is likely to be the dominant gas generated (Bonin et al., 2000; Norris, 2009). Generation and migration of these gases could affect the buffering capacity of the barrier by altering its physical and chemical properties. This phenomenon, which occurs in the longer term, has received less research attention than the short-term THM phenomena (Gens et al., 2001) and therefore the numerical models are underdeveloped in comparison (Pusch, 2008).

Norris (2009) summarised the gas flow processes in the context of a radioactive waste repository as characterised by Mallants and Jacques (2004) and Mallants et al. (2007) into the following four stages.

- Stage I: the generated gas can dissolve into the buffer pore water. Gas migration is by diffusion.

- Stage II: the gas generation rate exceeds the diffusive transport capacity of the dissolved gas, which leads to the formation of a free gas phase. Increasing gas pressure results in gradual desaturation of the buffer.

- Stage III: continuing gas generation will lead to increased pressures and the formation of a continuous gas phase. This stage initiates two-phase flow in the engineered barrier. Gas migration is mainly flow due to advection and further expulsion of water is expected.

- Stage IV: increasing gas pressures lead to flow through preferential pathways such as new pore space from dilation or micro/macro-fractures.

Norris (2009) suggested that in some cases where the gas entry pressure is higher than the minimum principal stress, the behaviour could move directly and abruptly from stage II to stage IV.

The aim of this work was to simulate numerically the behaviour of a compacted clay buffer subject to gas generation and migration from corrosion under a range of realistic conditions prior to any fracturing processes (i.e. before stage IV). The consequential gas pressure is then reported. In Section 2, the background to the work is considered. Section 3 presents an overview of gas generation rates, which provides an input into the model considered here. The theoretical formulation, including a boundary condition representing the corrosion process, is presented in Section 4, with the modelling approach presented in Section 5. The results of the simulations are presented and discussed in Section 6, with a consideration of the practical engineering relevance given in Section 7 .

This work was undertaken against a background of numerical model development within the scope of radioactive waste disposal at the Geoenvironmental Research Centre, Cardiff, and is integrated into the numerical code Compass (COde for Modelling PArtially Saturated Soil). The initial thermo-hydro-mechanical model was presented by Thomas and He (1998) and extension into chemical transport and reaction behaviour is described by Seetharam et al. (2011). Part of this work was initially presented in a report for the Nuclear Decommissioning Authority (Vardon et al., 2010). An initial model concerning reactive gas flow and behaviour, which complements this work, has since been produced (Masum et al., 2012).

\section{Background}

In recent years, extensive research activities have been carried out to investigate the THM behaviour of engineered buffers by means of both numerical and experimental investigations (e.g. Dixon et al., 2002; Pusch, 2001; Thomas et al., 2009, 2012). The majority of processes occurring are driven by the heat produced from the HLW and the water contained within natural bedrock. After this so-called thermal phase, the clay buffer is also likely to be fully saturated immediately adjacent to the canister, therefore anaerobic corrosion and production of repository gas can occur. The combination of long-term disposal and slow corrosion behaviour characterises the issue of gas generation and migration in buffers for radioactive waste disposal and also creates a challenging environment for research.

Several experimental programmes have been carried out by various researchers to understand the dominant mechanisms of 
gas transport through variably saturated compacted clays (e.g. Galle, 2000; Graham et al., 2002; Harrington and Horseman, 2003; Horseman et al., 1999; Pusch et al., 1985). In almost all of the programmes, a fully saturated buffer is considered, which results in extremely low gas permeability due to the pores being filled with pore water. Gas breakthrough (where gas is detected being released from the buffer) and pressure evolution are important features that have been recorded in the experiments. Various boundary conditions (e.g. flexible, restrained) and various gas injection rates or pressures have also been considered. In the majority of cases, flow by means of dilation/fracture processes has been concluded, occurring due to high gas pressures. A typical response found was that gas pressures were able to increase with only limited flow, until a critical pressure; thereafter, gas flow was able to occur more easily and pressure was reduced (Galle, 2000; Graham et al., 2002; Harrington and Horseman, 2003; Horseman et al., 1999; Pusch et al., 1985). Additionally, none of the experimental works showed a large degree of clay desaturation. However, it must be noted that the results of relatively short-term (for geological disposal) experimental studies cannot be fully conclusive as not all processes can be scaled with time and, in particular, all of the experiments used gas generation rates in excess of rates occurring due to corrosion.

The conceptualisation of gas migration phenomena through clays has been considered by a number of researchers. Ortiz et al. (2002) considered that, below the threshold pressure of gas entry, diffusion mechanisms play a dominant role in gas transport until a gas threshold pressure is exceeded and the clay fabric may deform. Rodwell et al. (1999) predicted that increasing gas pressure would simply force the clay minerals apart at the mouth of the largest pathway or where discontinuities already exist. It was further hypothesised by Alonso et al. (2006) and Olivella and Alonso (2008) that at high degrees of liquid saturation gas migration might take place as a combined phenomenon of two-phase flow and the development of pressure-induced pathways, with the pathways suggested to play a dominant role in low-permeability clays. It was, however, concluded by Birgersson et al. (2008) that a gas phase would not have access to pores filled with water because of the strong interaction between water molecules and counter ions and, therefore, for a gas to enter an initially saturated clay, consolidation of the clay-water system should take place. The model was verified with experimental results obtained by Harrington and Horseman (2003). Senger et al. (2008) carried out a numerical investigation of two-phase flow phenomena. It was suggested that desaturation of bentonite by displacement of generated hydrogen is unlikely and requires a pressure of more than $80 \mathrm{MPa}$. The pressure at this range is significantly higher than the minimum principal stress of a GDF. It was reported that gas pressure build-up was reduced, considering water consumption within the corrosion process, and that the gas pressure build-up under realistic corrosion conditions was unlikely to reach the pressures required for the fracture process. However, details of the gas migration processes and parameters used included within the model were not given, although both advective and diffusive gas flow were considered.

None of the models previously reported contain a full characterisation of realistic generation rates, water consumption and transport, liquid/gas advective transport, liquid/gas diffusive transport (including gas dissolution into water) and gas pressure evolution. It is these conditions that govern the migration of gas and the potential of gas to lead to dilatant/fracture flowing conditions; they are therefore important to understand prior to the onset of fractures. Should gas pressures increase and fracturing occur at a late stage, a number of models for pressure-induced fracturing exist, although they have not yet been applied to buffer materials for radioactive waste materials (e.g. Boone and Ingraffea, 1990; Réthoré et al., 2008; Secchi and Schrefler, 2012).

\section{Gas generation rates}

The gas generation rate, as input to the numerical model, is critical for understanding flow behaviour within the buffer material. A realistic rate allows both time and gradient-dependent processes to be appropriately considered.

Generation of gas in a high-level nuclear waste disposal facility occurs due to water vaporisation, water radiolysis, microbial activities and metallic corrosion (e.g. Bonin et al., 2000; Environment Agency, 2008). After the thermal phase, water vapour will be limited due to high water saturation, and microbial activities may reduce the net amount of gases due to metabolic activities (Ortiz et al., 2002). Therefore hydrogen gas generation due to metallic corrosion is thought to be the dominant generation mechanism (Kursten et al., 2004), with iron being the dominant metal.

Corrosion of the iron component of the waste-containing canisters under anaerobic conditions produces hydrogen gas $\left(\mathrm{H}_{2}\right)$ and a solid corrosion product, magnetite $\left(\mathrm{Fe}_{3} \mathrm{O}_{4}\right)$, as the dominant and stable chemical reaction under these conditions, which is described by the redox reaction I. Other reactions occur, for example creating ferrous hydroxide $\left(\mathrm{Fe}(\mathrm{OH})_{2}\right)$ which then converts thermodynamically to magnetite, water and hydrogen (e.g. Ortiz et al., 2002).

I. $3 \mathrm{Fe}+4 \mathrm{H}_{2} \mathrm{O} \leftrightarrow \mathrm{Fe}_{3} \mathrm{O}_{4}+4 \mathrm{H}_{2}$

This chemical reaction indicates that for each mole of hydrogen generated, $1 \mathrm{~mol}$ of water is consumed. Volckaert and Mallants (1999) estimated the kinetic hydrogen gas generation rate for a thin steel plate as

1. $R_{\mathrm{m}}=S R_{\mathrm{c}} \rho m \frac{f_{\mathrm{Fe}}}{M_{\mathrm{Fe}} / 1000}$

where $R_{\mathrm{m}}$ is the gas generation rate (mol/year), $S$ is the reactive 
surface area $\left(\mathrm{m}^{2}\right), R_{\mathrm{c}}$ is the corrosion rate (m/year), $\rho$ is the density (in this case of steel $\approx 7900 \mathrm{~kg} / \mathrm{m}^{3}$ ), $m$ is the stoichiometric factor, which for the chemical reaction mentioned above can be taken as $4 / 3$ for the generation of hydrogen (based on reaction I), $M$ is the molecular weight (in this case of iron $\approx 55.85 \mathrm{~g} / \mathrm{mol}$ ) and $f_{\mathrm{Fe}}$ is the fraction of iron in the steel, which has been taken as 0.99 for the steel canisters/iron overpack for HLW.

It is therefore the corrosion rate of iron within the metallic canisters that governs the generation of repository gases. The corrosion rate is also affected by environmental factors such as $\mathrm{pH}$, contact material, temperature, surface chemistry and the transport of corrosion products. Various experimental studies have been carried out under various environmental conditions (Kursten et al., 1996; Marsh and Taylor, 1988; Marsh et al., 1983; Papillon et al., 2003; Simpson and Valloton, 1986; Simpson et al., 1985; Smart et al., 2006; Taniguchi et al., 2004), with corroborating natural analogue studies (Miller et al., 2000). Gas generation data collated from the literature are shown in Figure 1, which reveals that there is over an order of magnitude difference among the reported values. These differences are likely to be due to the environmental factors listed above and measurement difficulties at low production rates. Additionally, further environmental changes may increase the range of corrosion possible (e.g. acidification due to dissolving hydrogen, increasing corrosion, or a protective iron oxide film reducing corrosion).

The corrosion rate is also dependent on the available moisture. Moisture is consumed within the corrosion reaction and then replacement moisture must be transported through the surrounding buffer before being available for further corrosion. Brown and Masters (1982) reported experiments on iron corrosion under atmospheric conditions that indicated a decrease in corrosion rate when the relative humidity dropped from $90 \%$ to $60 \%$. Thermodynamic considerations also predict that gas production stops when hydrogen partial pressure increases above $40 \mathrm{MPa}$ (Neretnieks, 1985); however, these pressures are unlikely to be sustained in a GDF due to lower in situ rock stresses.

\section{Theoretical formulation and key processes}

The model is formed with the following primary variables: pore water pressure, $u_{1}$; gas phase chemical species concentration, $c_{\mathrm{g}}^{i}$; liquid phase chemical species concentration, $c_{\mathrm{d}}^{i}$; and deformation, $\boldsymbol{u}$; the superscript $i$ refers to the chemical species in each case. This allows the formulation to consider multiple gases and dissolved chemical species, although in this work only hydrogen is considered. Here, it is assumed that the process is isothermal, but the absolute temperature $T$ is important in conversion from

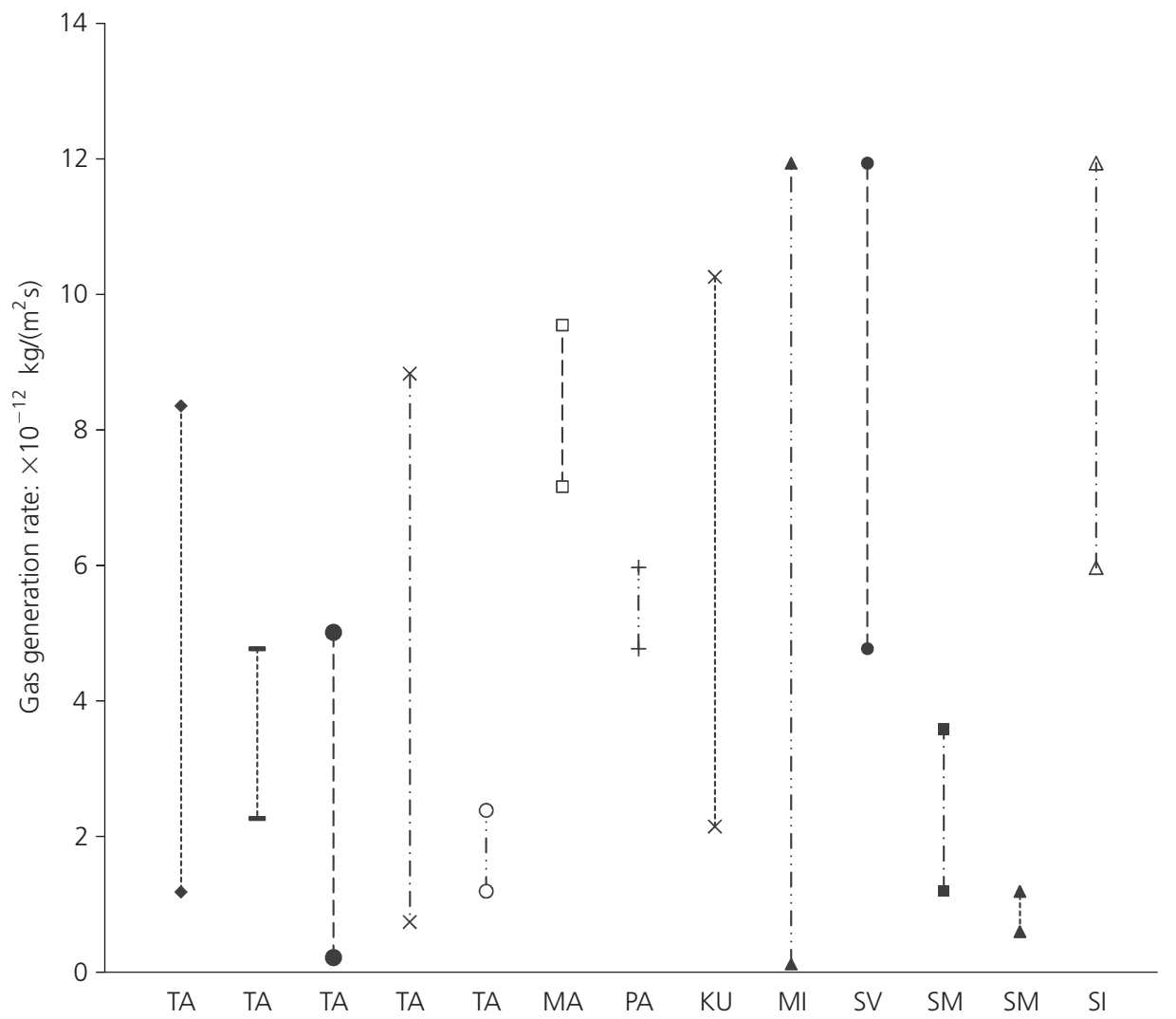

Figure 1. Experimental gas generation rates due to anaerobic iron corrosion reported in the literature



$-\triangleleft \cdot$ SI, Simpson et al. (1985) 
concentration to pressure and in future developments in the rate of chemical reactions; it is therefore included within the formulation, but not as a solvable primary variable. The formulation for moisture and deformation follows that of Thomas and He (1998), with the dissolved chemical behaviour following the work of Seetharam et al. (2011). Therefore, only the gas migration equation is described here in detail. The dissolved chemical equation is included because the migration of dissolved gas is important.

The gas phase is quantified by means of chemical concentration, for ease of converting into the liquid phase and so that geochemical reactions may be included later. The concentrations may be converted into pressure, by the ideal gas law

$$
\text { 2. } u_{\mathrm{g}}=\sum_{i=1}^{N} c_{\mathrm{g}}^{i} R T
$$

where $u_{\mathrm{g}}$ is the pore gas pressure, $N$ is the number of gas species and $R$ is the universal gas constant. The governing equation for gas migration is formed by the principle of conservation of mass

$$
\left(\begin{array}{l}
\text { Net rate of } \\
\text { change of moles }
\end{array}\right)=\left(\begin{array}{l}
\text { Net rate of } \\
\text { molar flux }
\end{array}\right)
$$

3.

$$
\pm\left(\begin{array}{l}
\text { Net rate of moles gained or lost } \\
\text { due to the source/sink }
\end{array}\right)
$$

The only sink/source terms considered in this work are from gas generation at the boundary or by the change of phase due to gas dissolution or effervescence, but can also be used for changes in chemical species due to chemical reactions. The governing equation (Equation 3) can be written

$$
\text { 4. } \frac{\partial\left(\theta_{\mathrm{g}} c_{\mathrm{g}}^{i} \partial V\right)}{\partial t}=\partial V \nabla\left(v_{\mathrm{g}}^{i}+v_{\mathrm{dg}}^{i}\right)-R_{\mathrm{g} \rightarrow \mathrm{d}}^{i}
$$

where $\theta_{\mathrm{g}}$ is the gas saturation, $\partial V$ is the incremental volume, $t$ is time, $v_{\mathrm{g}}^{i}$ is the advective gas flux of species $i, v_{\mathrm{dg}}^{i}$ is the diffusive gas flux and $R_{\mathrm{g} \rightarrow \mathrm{d}}^{i}$ is the sink/source term of gas species $i$ from gas to dissolved form. The advective flux is considered by Darcy's law and the diffusive flux is defined by Fick's law. The dissolved chemical governing equation can be defined in the same way as

$$
\text { 5. } \quad \frac{\partial\left(\theta_{1} c_{\mathrm{d}}^{i} \partial V\right)}{\partial t}=\partial V \nabla\left(v_{1}^{i}+v_{\mathrm{dl}}^{i}\right)-R_{\mathrm{d} \rightarrow \mathrm{g}}^{i}
$$

where $\theta_{1}$ is the liquid saturation, $v_{1}^{i}$ is the advective chemical flux, $v_{\mathrm{dl}}^{i}$ is the diffusive chemical flux and $R_{\mathrm{d} \rightarrow \mathrm{g}}^{i}$ is the sink/source term of gas species $i$ from dissolved to gas form. The advective flux is considered by Darcy's law of the pore water pressure and chemical concentration $\left(v_{1}^{i}=c_{\mathrm{d}}^{i} v_{1}\right.$, where $v_{1}$ is the Darcy liquid flux) and the diffusive flux is defined by Fick's law. Additionally, the sink/source terms in Equations 4 and 5 are equal and opposite (i.e. $R_{\mathrm{d} \rightarrow \mathrm{g}}^{i}=-R_{\mathrm{g} \rightarrow \mathrm{d}}^{i}$ ), conserving mass. Both sink/source terms encompass both dissolved-to-free gas and free gas-to-dissolved processes and represent the net effect.

The advective (Darcian) flux terms are defined as

6. $v_{\mathrm{x}}=\frac{K_{\mathrm{x}}}{\gamma_{\mathrm{x}}} \nabla\left(u_{\mathrm{x}}\right)$

where $\mathrm{x}$ represents either $\mathrm{g}$ (gas) or 1 (liquid), $K$ is the conductivity and $\gamma$ is the unit weight. The Fickian diffusion terms are defined as

7. $v_{\mathrm{dx}}^{i}=\operatorname{Sr}_{\mathrm{x}} D_{\mathrm{x}}^{i} \nabla\left(c_{\mathrm{x}}^{i}\right)$

where $\mathrm{Sr}$ is the degree of saturation and $D$ is the diffusion coefficient. The sink/source term is defined by use of Henry's law, relating the free and dissolved chemical species by Henry's coefficient of solubility $K_{\mathrm{H}}$

8. $c_{\mathrm{d}}^{i}=K_{\mathrm{H}} c_{\mathrm{g}}^{i}$

It is noted that $K_{\mathrm{H}}$ varies proportionally with gas pressure under isothermal conditions.

\subsection{Corrosion boundary conditions}

Casting Equation 1 as the generation rate per area and multiplying by the molecular weight of hydrogen and water respectively gives the fluxes, if water is available from the buffer for the corrosion process

9. $R_{\mathrm{g}}=\frac{R_{\mathrm{m}} M_{\mathrm{H}_{2}}}{S}$

10. $R_{\mathrm{w}}=-\frac{R_{\mathrm{m}} M_{\mathrm{H}_{2} \mathrm{O}}}{S}$

It is assumed that the water is able to reach the steel at an equal rate independent of time beyond the buffer boundary; that is, corrosion products do not incrementally impede the water movement over time within the steel. However, this effect could be included by means of modification to the corrosion rate $R_{\mathrm{c}}$ in Equation 1.

The maximum boundary fluxes can be written as a function of each other and linked by 
11. $R_{\mathrm{w}}=-\alpha R_{\mathrm{g}}$

where $\alpha$ is the ratio of molecular weights. To allow for the observed decrease in corrosion rate when the relative humidity reduces, the factor $d=f(\mathrm{Sr})$ is introduced, yielding the final form of the fluxes as

12. $q_{\mathrm{g}}=d R_{\mathrm{g}}$

13. $q_{\mathrm{w}}=-d \alpha R_{\mathrm{g}}$

The function $d$ has been given two possible forms due to a lack of information. The first is referred to as a step-change condition where, above a critical degree of water saturation $\mathrm{Sr}_{\mathrm{c}}, d=1$ and below the critical degree of water saturation $d=0$. The second is where, above the same critical value of degree of saturation, $d$ increases from 0 to 1 at $S_{\mathrm{r}}=1$. In this case, a linear expression has been adopted as a first approximation due to a lack of data.

\section{Modelling approach}

The theoretical model was numerically implemented into a finiteelement model. A series of one-dimensional analyses based on a series of illustrative realistic scenarios was undertaken. The domain is based on the KBS-3V reference concept (SKB, 2006) - copper canisters with cast iron inserted vertically at a depth of approximately $500 \mathrm{~m}$ in saturated granite rock with a compacted bentonite buffer. Realistic material parameters were used for all materials in the domain (e.g. from the Hard Rock Laboratory in Sweden and the buffer material used in the SKB Prototype Repository (e.g. Johannesson et al., 2007)), but are excluded here for brevity; a full description is given by Vardon (2009). The soil water characteristic curve is noted to have an air entry value of approximately $10 \mathrm{MPa}$, therefore any desaturation is likely to occur due to water consumption and not two-phase flow. The material parameters and fluxes that are varied are defined in Section 5.1. Gas generation and water consumption due to metallic corrosion are represented by boundary conditions at the buffer boundary. Hydrostatic boundary conditions for a depth of $500 \mathrm{~m}$ and gas saturation are considered at the far-field boundary as a conservative condition. The domain is illustrated in Figure 2. For the analyses, the buffer was discretised into 20 finite elements and the host rock into 50 finite elements with smaller elements nearer to the boundary where flux conditions were applied and higher gradients expected. Simulation results were checked for spatial and temporal convergence by halving both the timestepping regime and spatial discretisation and checking that the results were within $1 \%$ tolerance. A variable time-step regime was used to allow the time-step to increase or decrease, depending on convergence criteria.

Should the gas pressure reach the sum of the pore pressure and swelling pressure of the bentonite (the fracturing threshold), there is a possibility of pneumatic fracture occurring. Full confirmation of this value is required experimentally. In this work (supported by large-scale experimentation (Johannesson et al., 2007)) the value was set at $10 \mathrm{MPa}$.

\subsection{Scenarios}

The parameters developed include the major material parameters and boundary conditions governing

dissolved diffusive gas transport

advective transport of gas and water

gas generation.

These parameters are the dissolved diffusion, intrinsic permeability and the gas generation rate. For these parameters, realistic maximum and minimum scenarios were considered, as shown in Table 1 . The simulations are isothermal, with the temperature set at $293 \mathrm{~K}$.

\section{Discussion}

A selection of simulation results is now presented. The results are shown in terms of gas pressure evolution at the buffer domain boundary, which is the highest pressure in the domain. Figure 3 shows the results of the analysis using the mid-point values from Table 1. The figure shows that the maximum gas pressure is approximately $0.55 \mathrm{MPa}$, therefore in this case there is no risk of pneumatic fracture.

Figure 4 shows the results of a series of analyses with mid-point intrinsic permeability, including the upper and lower generation rates and upper and lower dissolved diffusion coefficients. The highest pressure reached is approximately $1.6 \mathrm{MPa}$ with the lowest diffusion coefficient and the highest generation rate. This demonstrates that, under realistic gas generation conditions, there is little



Figure 2. Model domain 


\begin{tabular}{lccc}
\hline & Maximum & Mid-point & Minimum \\
\hline Gas generation rate: $\mathrm{kg} /\left(\mathrm{m}^{2} \mathrm{~s}\right)$ & $2.0 \times 10^{-10}$ & $2.0 \times 10^{-11}$ & $2.0 \times 10^{-12}$ \\
Dissolved diffusion coefficient: $\mathrm{m}^{2} / \mathrm{s}$ & $2.0 \times 10^{-11}$ & $1.1 \times 10^{-11}$ & $2.0 \times 10^{-12}$ \\
Intrinsic permeability: $\mathrm{m}^{2}$ & $1.0 \times 10^{-19}$ & $5.0 \times 10^{-20}$ & $1.0 \times 10^{-21}$
\end{tabular}

Table 1. Scenario parameters

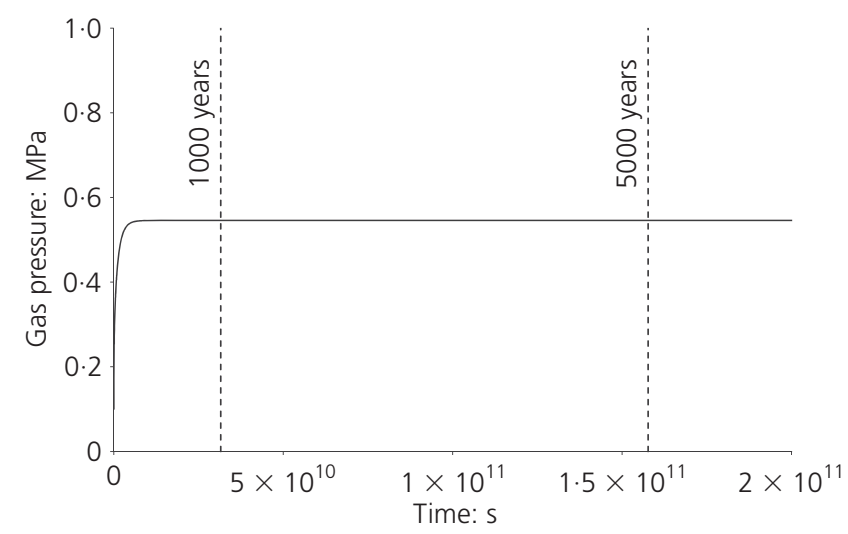

Figure 3. Pore gas pressure evolution of the base case scenario

chance of pneumatic fracturing, with the maximum pressure achieved in the envelope simulations being about $20 \%$ of the likely fracturing threshold. This pressure does not occur until approximately 1000 years of corrosion and gas generation, illustrating the importance of understanding the long-term behaviour of the repository system. In this timescale, mineralogical change due to gas dissolution is also possible and must be further considered.

The gas pressure rate was found to be negligibly different in relation to varying the intrinsic permeability, therefore the pore water pressure was investigated. These results are shown in Figure 5 with the maximum realistic gas generation rate and therefore maximum water consumption rate. The pore water pressure results are also not influenced by a differing dissolved diffusion coefficient. It is shown that, while a reduced pore water pressure is exhibited with the minimum intrinsic permeability, the buffer remains saturated. This behaviour explains why the gas pressure is invariant with intrinsic permeability.

\section{Practical relevance and potential applications}

The work reported in this paper contributes to the analysis of radioactive waste repositories. The behaviour exhibited is likely to occur in the period when the radioactive waste reduces heat output and the buffer is saturated. The generation of gas by

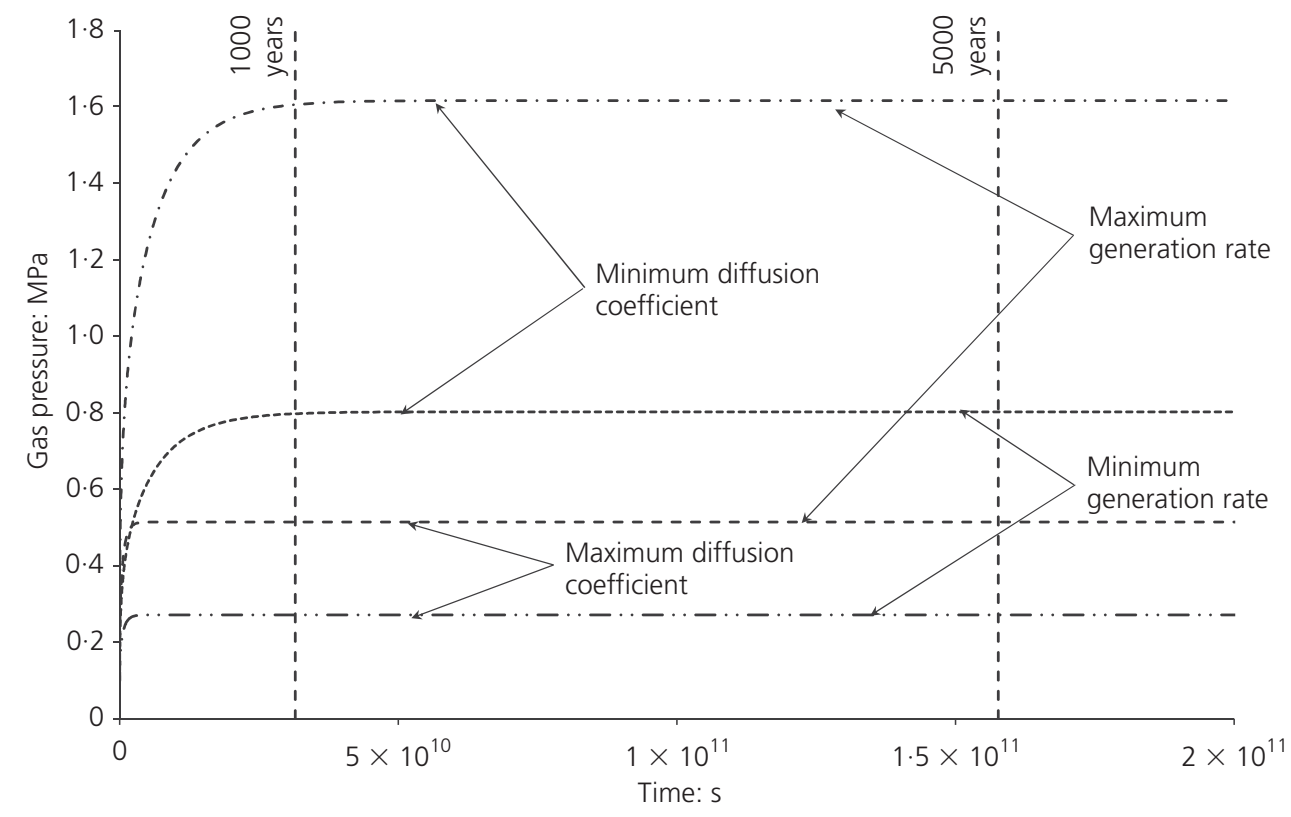

Figure 4. Pore gas pressure evolution with reference to changes in diffusion rate and realistic generation rates (maximum and minimum) 
Simulation of repository gas migration in a bentonite buffer

Vardon, Thomas, Masum, Chen and Nicholson

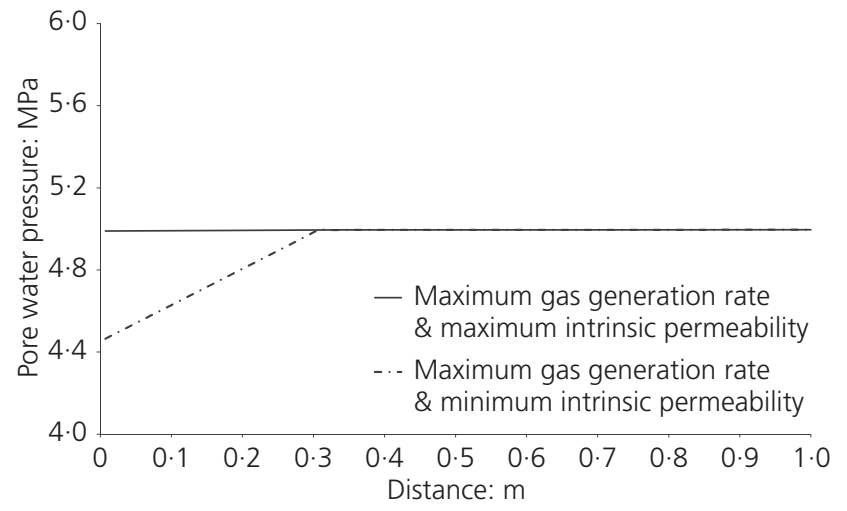

Figure 5. Pore water profile along the buffer $(300 \mathrm{~mm})$ and rock in relation to a change in intrinsic permeability with maximum gas generation and water consumption rate at steady state

means of anaerobic metallic corrosion will occur and the gas must be able to migrate away from the repository for the repository to fulfil its function. The conceptual behaviour of gas migration has been recently investigated and a range of migration mechanisms have been identified. In addition, experimental investigations have been undertaken to further understand and quantify possible migration mechanisms. However, this work illustrates the importance of investigating these processes over realistic timescales and conditions. For some practical problems (e.g. radioactive waste disposal), this is only practically achieved by numerical simulation, where timescales can be measured in hundreds of years. This work has additional applications in both gas transport phenomena and long-term analysis, such as the long-term assessment of carbon dioxide sequestration.

\section{Conclusion}

An investigation into the ranges of gas pressures expected in a HLW repository has been presented. The gas, mainly generated by metallic (iron) corrosion, must migrate through a compacted clay buffer and the host rock. A model of gas transport is presented in the frame of coupled hydraulic, chemical and mechanic behaviour, and includes both gas generation and water consumption from the corrosion process. A practical range of gas generation rates has been established from available data on the corrosion process along with the available ranges of material properties for a compacted bentonite buffer. A number of scenarios have been developed, considering corrosion processes and buffer properties, and finite-element numerical simulations were then undertaken for these scenarios. It was found that, in all realistic cases, including realistic maxima and minima considered, the risk of pneumatic fracture was negligible. The main advantage of undertaking this work by means of numerical analysis is with regard to the long timescales at which these processes occur and the ability to analyse a range of realistic results and outcomes quickly. This study was undertaken as a generic scoping exercise and in many cases there is not yet enough experimental evidence fully to support all material parameter selections and characterise the material behaviour due to the long timescales over which the processes act.

\section{Acknowledgements}

Shakil Al Masum gratefully acknowledges the financial and technical support from the Geoenvironmental Research Centre at Cardiff University and Ove Arup \& Partners.

\section{REFERENCES}

Alonso EE, Olivella S and Arnedo D (2006) Mechanism of gas transport in clay barriers. Journal of Iberian Geology 32(2): 175-196.

Birgersson M, Akesson M and Hokmark H (2008) Gas intrusion in saturated bentonite - a thermodynamic approach. Physics and Chemistry of Earth 33(S1): S248-S251.

Bonin B, Colin M and Dutfoy A (2000) Pressure building during the early stages of gas production in a radioactive waste repository. Journal of Nuclear Materials 281(1): 1-14.

Boone TJ and Ingraffea AR (1990) A numerical procedure for simulation of hydraulically driven fracture propagation in poroelastic media. International Journal for Numerical and Analytical Methods in Geomechanics 14(1): 27-47.

Brown PW and Masters LW (1982) Factors affecting the corrosion of metals in the atmosphere. In Atmospheric Corrosion (Ailor WH (ed.)). Wiley, New York, NY, USA, pp. 31-49.

CoRWM (Committee on Radioactive Waste Management) (2006) Managing our Radioactive Waste Safely. CoRWM's Recommendations to Government. CoRWM, London, UK.

Dixon D, Chandler N, Graham J and Gray MN (2002) Two largescale sealing tests conducted at Atomic Energy of Canada's underground research laboratory: the buffer container experiment and the isothermal test. Canadian Geotechnical Journal 39(3): 503-518.

Environment Agency (2008) Gas Generation and Migration from a Deep Geological Repository for Radioactive Waste, $A$ Review of Nirex/NDA's Work. Environment Agency, Bristol, UK.

Galle C (2000) Gas breakthrough pressure in compacted Fo-Ca clay and interfacial gas overpressure in waste disposal context. Applied Clay Science 17(1-2): 85-97.

Gens A, Olivella S and Vallejan B (2001) Analysis of gas phase transport phenomena in compacted clay barriers. Proceedings of 10th International Conference of Computational Methods in Advance Geomechanics, Tucson, AZ, USA, pp. 735-742.

Graham J, Halayko KG, Hume H et al. (2002) A capillarityadvective model for gas break-through in clays. Engineering Geology 64(2-3): 273-286.

Harrington JF and Horseman ST (2003) Gas Migration in KBS-3 Buffer Bentonite. SKB, Stockholm, Sweden, Technical report 03-02.

Horseman ST, Harrington JF and Sellin P (1999) Gas migration in clay barriers. Engineering Geology 54(1-2): 139-149.

Johannesson LE, Börgesson L, Goudarzi R et al. (2007) Prototype repository: a full scale experiment at Äspö HRL. Physics and Chemistry of the Earth 32(1-7): 58-76. 
Kursten B, Cornelis B, Labat S and Van Iseghem P (1996) Geological Disposal of Conditioned High Level and Long Lived Radioactive Waste. In Situ Corrosion Experiments. SCK-CEN, Mol, Belgium, Report R-3121.

Kursten B, Smailos E, Azkarate I et al. (2004) COBECOMA: State of Art Document on the Corrosion Behaviour of Container Materials. EC, Luxembourg.

Mallants D and Jacques D (2004) Performance Assessment for Deep Disposal of Low and Intermediate Level Short-lived Radioactive Waste in Boom Clay. SCK-CEN, Mol, Belgium, Report R-3793.

Mallants D, Jacques D and Perko J (2007) Modelling multi-phase flow phenomena in concrete barriers used for geological disposal of radioactive waste. Proceedings of 11th International Conference on Environmental Remediation and Radioactive Waste Management, ICEM07, Bruges, Belgium, pp. 741-749.

Marsh GP and Taylor KJ (1988) An assessment of carbon steel containers for radioactive waste disposal. Corrosion Science 28(3): 289-320.

Marsh GP, Bland IW, Desport JA et al. (1983) Corrosion assessment of metal overpacks for radioactive waste disposal. European Applied Research Reports - Nuclear Science Technology 5(2): 223-252.

Masum SA, Vardon PJ, Thomas HR, Chen Q and Nicholson D (2012) Multicomponent gas flow through compacted clay buffer in a higher activity radioactive waste geological disposal facility. Mineralogical Magazine 76(8): 3337-3344

Miller W, Alexander R, Chapman N, McKinley I and Smellie J (2000) Geological disposal of radioactive wastes \& natural analogues. Waste Management Series 2. Pergamon, Amsterdam, the Netherlands.

Neretnieks I (1985) Some Aspects of the Use of Iron Canisters in Deep Lying Repositories for Nuclear Waste. NAGRA, Wettingen, Switzerland, Technical report NTB 85-35.

Norris S (ed.) (2009) Summary of Gas Generation and Migration - Current State-of-the-Art. EC, Luxembourg, FORGE Report D1.2.

Olivella S and Alonso EE (2008) Gas flow through clay barriers. Géotechnique 58(3): 157-176.

Ortiz L, Volckaert G and Mallants D (2002) Gas generation and migration in Boom Clay, a potential host rock formation for nuclear waste storage. Engineering Geology 64(2-3): $287-$ 296.

Papillon F, Jullien M and Bataillon C (2003) Carbon steel behaviour in compacted clay: two long term tests for corrosion prediction. In Prediction of Long Term Corrosion Behaviour in Nuclear Waste Systems. Institute of Materials, Minerals and Mining, London, UK, European Federation of Corrosion publication no. 36, pp. 439-454.

Pusch R (2001) The Buffer and Backfill Handbook. Part 2: Materials and Techniques. SKB, Stockholm, Sweden, TR-02-12.

Pusch R (2008) Geological Storage of Highly Radioactive Waste. Springer, New York, NY, USA.

Pusch R, Ranhagen L and Nilsson K (1985) Gas Migration through Mx-80 Bentonite. NAGRA, Wettingen, Switzerland, Technical report NTB 85-36.

Réthoré J, de Borst R and Abellan MA (2008) A two-scale model for fluid flow in an unsaturated porous medium with cohesive cracks. Computational Mechanics 42(2): 227-238.

Rodwell WR, Harris AW, Horseman ST et al. (1999) Gas Migration and Two-phase Flow through Engineered and Geological Barriers for a Deep Repository for Radioactive Waste. Office for Official Publications of the European Communities, Brussels, Belgium, Joint EC/NEA status report, EUR $19122 \mathrm{EN}$

Secchi S and Schrefler BA (2012) A method for 3-D hydraulic fracturing simulation. International Journal of Fracture 178(1-2): 245-258.

Seetharam SC, Thomas HR and Vardon PJ (2011) Non-isothermal multi-component reactive transport model for unsaturated soil. ASCE International Journal of Geomechanics 11(2): 84-89, http://dx.doi.org/10.1061/(ASCE)GM.19435622.0000018

Senger R, Marschall P and Finsterle S (2008) Investigation of two phase flow phenomena associated with corrosion in an $\mathrm{SF} /$ HLW repository in Opalinus Clay, Switzerland. Physics and Chemistry of the Earth 33(S1): S317-S326.

Simpson JP and Valloton PH (1986) Experiments on Container Materials for Swiss High-level Waste Disposal Projects, Part III. Nagra, Wettingen, Switzerland, Technical report NTB 86-25.

Simpson JP, Schenk R and Knecht B (1985) Corrosion rate of unalloyed steels and cast irons in reducing granitic groundwaters and chloride solutions. Materials Research Society Symposium Proceedings 50: 429-436.

SKB (2006) Long-term Safety for KBS-3 Repositories at Forsmark and Laxemar - A First Evaluation. Main Report of the SRCan Project. SKB, Stockholm, Sweden, Technical report 06-09.

Smart NR, Rance AP and Fennell AH (2006) Expansion Due to the Anaerobic Corrosion of Iron. SKB, Stockholm, Sweden, Technical report 06-41.

Taniguchi N, Kawasaki M, Kawakami S and Kubota M (2004) Corrosion behaviour of carbon steel in contact with bentonite under anaerobic condition. In Prediction of Long Term Corrosion in Nuclear Waste Systems. European Federation of Corrosion and Andra, Nice, France, pp. 24-34.

Thomas HR and He Y (1998) Modelling the behaviour of unsaturated soil using an elasto plastic constitutive relationship. Géotechnique 48(5): 589-603.

Thomas HR, Cleall PJ, Dixon D and Mitchell HP (2009) The coupled thermal-hydraulic-mechanical behaviour of a large-scale in situ heating experiment. Géotechnique 59(4): 401-413.

Thomas HR, Sedighi M and Vardon PJ (2012) Diffusive reactive transport of multicomponent chemicals under coupled thermal, hydraulic, chemical and mechanical (THCM) conditions. International Journal of Geomechanics 30(4): 841-857, http://dx.doi.org/10.1007/s10706-012-9502-9.

Vardon PJ (2009) A Three-dimensional Numerical Investigation 
of the Thermo-hydro-mechanical Behaviour of a Large-scale Prototype Repository. $\mathrm{PhD}$ thesis, Cardiff School of Engineering, Cardiff University, UK.

Vardon PJ, Masum S and Thomas HR (2010) Initial Investigation of

Gas Pressure Data Ranges for Use in the Post Closure Disposal System Safety Case. Report undertaken for the Nuclear Decommissioning Authority in conjunction with Arup.
Volckaert G and Mallants D (1999) De Gasproblematiek bij het Bergen van Radioactief afval in een diepe Geologische Berging in de klei van Boom. SCK-CEN, Mol, Belgium, Report R-3287 (in Dutch).

Yong RN, Pusch R and Nakano M (2010) Containment of HighLevel Radioactive and Hazardous Solid Wastes with Clay Barriers. Spon Press, New York, NY, USA.

\section{WHAT DO YOU THINK?}

To discuss this paper, please email up to 500 words to the editor at journals@ice.org.uk. Your contribution will be forwarded to the author(s) for a reply and, if considered appropriate by the editorial panel, will be published as a discussion in a future issue of the journal.

Proceedings journals rely entirely on contributions sent in by civil engineering professionals, academics and students. Papers should be $2000-5000$ words long (briefing papers should be 1000-2000 words long), with adequate illustrations and references. You can submit your paper online via www.icevirtuallibrary.com/content/journals, where you will also find detailed author guidelines. 